https://helda.helsinki.fi

\title{
Journalism and Witnessing
}

\section{Pantti, Mervi Katriina}

Routledge

2019-04

Pantti , M K 2019 , Journalism and Witnessing . in K Wahl-Jorgensen \& T Hanitzsch (eds), The Handbook of Journalism Studies . 2nd Edition edn , ICA Handbook Series, Routledge , New York and London , pp. 151-164 . https://doi.org/10.4324/9781315167497-10

http://hdl.handle.net/10138/308649

https://doi.org/10.4324/9781315167497-10

acceptedVersion

Downloaded from Helda, University of Helsinki institutional repository.

This is an electronic reprint of the original article.

This reprint may differ from the original in pagination and typographic detail.

Please cite the original version. 


\title{
Journalism and witnessing
}

\author{
Mervi Pantti
}

\section{Introduction}

Changes in media technologies have spurred new practices and forms of witnessing and accordingly, stimulated research on witnessing in the field of journalism. Witness testimonies offering firsthand evidence about critical situations have multiplied; today, acts of witnessing potently gain visibility worldwide as they circulate in multiple online forums and media.

Witnessing has become one of the primary political acts through which civil society actors attempt to intervene in present global injustices, as well as have become a defining mode of popular understanding of past brutalities (Bradford, 2014; Givoni, 2014; Kurasawa, 2009; Zelizer, 1998). Through the institutionalized practice of witnessing, journalism has played an important role in maintaining its political and cultural significance. Witnessing remains a central practice of journalists, giving meaning to what they do or are expected to do when encountering conditions of oppression and suffering, typically in the contexts of wars, conflicts and disasters.

Witnessing is a complex concept in literature, including journalism scholarship. In recent decades, the meaning of witnessing has expanded well beyond its traditional definition of testifying from personal observation. In this process of augmentation and popularization, the concept has evolved to perform various rhetorical and analytical functions and consequently, requires constant clarification and new categorizations. The attempts to redefine and clarify witnessing in the global media environment are seen in the emergence of new composite concepts typically pointing to the affordances of new communication technologies, including “mobile witnessing” (Reading, 2009), “connective witnessing” (Mortensen, 2015), "networked witnessing” (Ananny, 2015), "immersive witnessing" (Nash, 2017) or "self-represented witnessing" (Rae, Holman \& Nethery, 2018). 
In this dynamic context, I attempt to trace how the concept of witnessing has been defined in journalism and interdisciplinary scholarship and how witnessing has contributed to our understanding of journalism and its role in interpellating audiences as witnesses of significant events. This chapter focuses on the key issues that have preoccupied the scholarship examining witnessing and mass media: the construction of authority, authenticity and moral responsibility in different forms of witnessing acts. What are journalists doing when they purport to bear witness? How does the idea of witnessing relate to journalism's practices and norms? What is the role of eyewitness accounts in journalism's claims to truth? How are new digital technologies shaping witnessing as a cultural practice and political act? These are the questions that I attempt to answer in this chapter. In the next section, I introduce witnessing as a communicative act and discuss the role of witnessing in public culture drawing on the foundational contributions to witnessing literature, before discussing "bearing witness" and "eyewitnessing" in journalism. Then I discuss audiences as secondhand witnesses to mediated witness accounts and consider the role of new communication technologies in shaping contemporary rituals and politics of witnessing.

\section{Witnessing as a communicative act}

Research on the public act of witnessing began to thrive in the 1980s (e.g., Felman \& Laub, 1992; Wieviorka, 1998). Although witness testimonies did not form a new genre, they burgeoned after the Second World War, in response to the Holocaust and subsequent atrocities and humanitarian disasters worldwide. The cultural prevalence of and wide interest in life narratives, individual experiences and emotions are discussed in Wieviorka's book The Era of Witness (1998). She pays particular attention to Holocaust testimonies and their impact on the public knowledge of these events in subsequent decades. Wieviorka (2006, p. 389) identifies the 1961 Eichmann trial in Jerusalem as the advent of the "era of [the] witness." As explained by Attorney General Gideon Hausner (as cited in Wieviorka, 2006, p. 390), the purpose of the witness is not only to uncover the 
truth about the event but also to tell a story based on personal observations and experiences that could "reach the hearts of men" and convey a moral judgment of what happened.

In the first-generation scholarship on witnessing emerging above all from the humanities and psychology, the concept of a witness stresses a firsthand experience of a traumatic event. To qualify as a witness, someone should have personally lived through a traumatic event and endured bodily suffering. To witness is not a choice but an imperative. As Douglass and Vogler (2003, p. 10) write, a horrendous event interpellates its witnesses by inflicting physical and emotional injury on them. As shown in Hausner's depiction, rather than merely a matter of telling facts about the occurrence, witnessing is summoned in order to appeal to someone. Witnessing is understood as a dialogical communicative act aiming to "to address another, to impress upon a listener, to appeal to a community" (Felman \& Laub, 1992, p. 204). The practice of witnessing, therefore, requires the witness who publicly narrates personal suffering and the audience who is addressed by andhopefully_moved by the witness's account, so that the audience members become future witnesses in turn (Bradford, 2014, p. 208).

Witnessing is inevitably tied to transforming events, either materially by altering their course or subsequently impacting our understanding of and response to a horrific event (e.g., Thomas, 2009; Zelizer, 1998, p. 10). According to Zion and colleagues (2012, p. 73), witnessing “acts as testimony from which [political] action can begin." Scholars have also emphasized the personal consequences of witnessing: Witness accounts function to reassure the victims that they have not been abandoned and forgotten (Ibid.). The most common trope of public culture and academic research concerning witnessing is an assertion that horrendous events - the Holocaust, Hiroshima, Vietnam, Bosnia, Rwanda and many other past situations of unthinkable violenceshould never be forgotten but be kept alive by acts of mediated witnessing in order to redeem the victims' suffering and prevent recurrences of such violence (Bradford, 2014, p. 205). In the context of journalism, scholars have argued that news media, and the visual coverage in particular, play a 
key role in transforming the collective trauma into a collective recovery (Zelizer \& Allan, 2002, p. 2).

In media and journalism studies, the complex communicative relationship between firsthand witnesses and the audience receiving the witness accounts has been at the core of scholarly debates (Boltanski, 1999; Peters, 2001). In a seminal article, Peters (2001, p. 23) defines witnessing as "an intricately tangled practice" that involves ordinary people who can be "witnesses in media (the vox pop interview, 'tell us how it happened'), of media (members of studio audience), and via media (watching history unfold at home in their armchairs)" and the media, which makes audiences secondhand witnesses by mediating witness narratives. This tripartite interrelationshipamong witnesses who appear in the media, the media (journalists) themselves acting as witnesses through their narratives and the audiences as witnesses to mediated events - becomes established in media studies.

Peters" (2001) distinction between witnessing as "seeing" and witnessing as "saying" has become the central issue in journalism studies on witnessing. "Seeing" refers to passively observing significant events, whereas "saying" involves actively producing and disseminating knowledge and thus, taking responsibility for such events, authenticated by the bodily presence of the witness. There is agreement in the literature that being a spectator to mediated forms of witnessing without taking responsibility as a political agent is not sufficient to qualify as witnessing (Boltanski, 1999; Chouliaraki, 2009; Zelizer, 2004, pp. 115-135). The practice of witnessing is first a vehicle for creating new witnesses, that is, obliging audiences as secondhand witnesses to speak and intervene in the present injustices (Givoni, 2014). In the next section, I discuss literature that has addressed journalistic witnessing as a morally and politically meaningful act.

\section{Journalists bearing witness}


As professional witnesses, journalists turn testimonies of firsthand witnesses into narratives (Ashuri \& Pinchevski, 2009, p. 143). In journalism scholarship, a key question is how journalists' witnessing differs from other reporting practices. Tait (2011) argues that in the contemporary ubiquitous media landscape, it is crucial to distinguish between active and passive witnessing. She proposes using the concept of "bearing witness" when referring to active moral engagement in violent and tragic events. Journalistic reporting is normatively based on eyewitnessing, which necessitates detachment and objectivity, while bearing witness necessarily involves an attempt to change the witnessed reality by eliciting an affective experience that incites the audience's action (Tait, 2011, p. 1227). Bearing witness, then, is essentially driven by a moral purpose and is not merely geared toward transmitting information about the event (Peters, 2001; Tait, 2011). The morality of bearing witness is fundamentally bound to the recognition of other people's suffering and traumatic experiences (Felman, 1992, p. 204; Peters, 2001; Rentschler, 2004; Sontag, 2003). Bearing witness involves reconstituting and communicating other people's experiences of pain and loss to the wider world in ways that encourage the receivers of the message to take action in response to situational or structural violence. As Tait (2011, p. 1227) sums up, bearing witness is a site for the transmission of moral responsibility.

Sociologist Fuyuki Kurasawa (2009, p. 95) conceptualizes bearing witness as a "globalizing mode of ethico-political labour" to combat global injustices. In discussing what constitutes bearing witness, he identifies (using the message-in-a-bottle allegory) crucial tasks and perils that must be performed and overcome for witnessing to succeed. These tasks are illustrative for assessing journalists' narratives of critical moments:

Giving voice to mass suffering against silence (what if the message is never sent or does not reach land?); interpretation against incomprehension (what if it is written in a language that is undecipherable?); the cultivation of empathy against indifference (what if, after being read, it is discarded?); remembrance against forgetting (what if it is distorted or erased over time?); 
and prevention against repetition (what if it does not help to avert other forms of suffering?).

(Kurasawa, 2009, p. 95)

This outline of necessary responsibilities includes fundamental tenets of modern journalism and journalistic roles in reporting on large-scale tragedies. Making specific instances of injustices and suffering visible, intelligible and relevant for distant audiences forms the foundation of reporting on atrocities, wars and disasters (Pantti, Wahl-Jorgensen \& Cottle, 2012). As Sambrook (2010) argues, foreign reporting in the 1930s and the 1940s (most notably about the concentration camps) focused on the victims, and the humanitarian consequences set examples for narratives about traumatic events in the future. Such narratives also constitute an important source of shared understandings of the past (Felman \& Laub, 1992; Kitch, 2008; Thomas, 2009; Zelizer, 1998, 2002).

Making suffering visible and giving voice to the victims sits easily with the idea of "good journalism," particularly with the professional ideals of exposing injustices and promoting equality to improve the conditions of the socially disadvantaged. Firsthand eyewitness accounts have long constituted a central element of media reporting of war, atrocities and disasters (Frosh \& Pinchevski, 2009; Pantti \& Wahl-Jorgensen, 2012; Wiesslitz \& Ashuri, 2011). Global news providers and new technologies, such as videophones, social media and images from satellites and drones, have made the invisibility of humanitarian disasters less likely (Cottle, 2014). Such technologies employed by journalists have arguably also contributed to the acknowledgment of wrongdoings and suffering, and help give voice to the previously unimportant and voiceless.

However, the suffering that gains entry into public knowledge and collective remembering is that judged worthy of knowing, caring and remembering by the media. How witnessing is framed is vitally important as it can either open up or exclude "certain kinds of questions, certain kinds of historical inquiries" (Butler, 2004, p. 4). Media representations and frames that shape our responses to global injustices and horrors of war create a distinction between those lives that are recognized as fully human and "grievable," and those that are not (Butler, 2009). As Cottle (2013, p. 233) argues, 
journalists' work is continuously impacted by an institutionalized "calculus of death," referring to routine judgments about the importance and appeal of news stories that are informed by cultural norms, the political context and organizational resources.

The cultivation of empathy in news storytelling, essential in mobilizing the audience to action, is a controversial issue in the journalism profession. The news media have no political or commercial obligation to provide content that elicits affective responses from the audience to mobilize them to take public action against injustice and violence (Rentscler, 2004). From the ethical perspective, it is also clear that the practice of bearing witness to mass suffering in the sense of active involvement calls into question journalism's core ideals of striving for objectivity and detachment. The norms and conventions of impartial and uninvolved reporting demand that explicit moral commentary, emotional appeals or expressions of emotion be prohibited in professional journalism (Wahl-Jorgensen, 2013).

Examining non-professional journalist-activists witnessing the plight of Palestinians at Israeli checkpoints, Wiesslitz and Ashuri (2011) argue that the Internet has facilitated the emergence of "the moral journalist" model. This model is different from the presumably objective reporting of professional journalists in that these "moral journalists" incorporate their feelings about the suffering they observe in their testimonies, "revealing the inner 'truth' of the witness" (p. 1044). However, the digital media environment has also opened up more space for personalized and emotional forms of storytelling by professional journalists. Despite the professional obligation to minimize journalists' own presence in the narratives, there are frequent cases where journalists' personal opinions and experiences are highlighted. As Peters (2001, p. 717) states, witnessing draws upon a relation of intimacy between the journalist and the audience. Journalists' emotional expression is pivotal to witnessing because the emotional expression works to bring viewers who do not have firsthand experiental access to the event closer to it. Certainly, the boundaries between eyewitnessing and bearing witness, as well as engaging in others' experiences yet remaining 
detached, are porous. How these boundaries materialize is connected not only to normative ideas of journalism and journalists' roles but also to affordances and conventions of media forms and technologies, as well as to the specificities of the event. Witnessing is shaped by various situational, technological and practical factors (Ashuri \& Pinchevski, 2009, p. 136; Wang, Lee \& Wang, 2013). For instance, journalists tend to employ more opinionated and emotional reporting styles in tweets that offer a new medium to bear witness to violent events (Pantti, 2017).

Alongside mainstream journalism that idealizes objectivity and is not explicitly driven by the moral duty to increase awareness of global injustices, models of a morally driven journalism have long existed (e.g., Plaisance, 2002; Wiesslitz \& Ashuri, 2011). Providing an example of such a moral position, Tait (2011) analyzes Nicholas Kristof's columns in the New York Times about the humanitarian crisis in Darfur in terms of the ways that they enact responsibility through narrative engagement. Kristof's status as an op-ed columnist enables him to exceed the normative journalistic position of impartiality. Kristof reveals how it feels to observe atrocities, exposing the typically hidden affective dimensions of journalistic practice, and attempts to generate powerful emotionshorror, anger, shame and pity - to move his audience to political action (p. 1228). His bearing witness that exceeds objectivity is authorized by having personally seen the horrors, as well as by the moral and emotional shock caused by the witnessed event.

\section{Journalists as eyewitnesses}

"Being there" is the ontological foundation of witnessing (Peters, 2001, p. 710). Being there at the scene providing firsthand reports lends credibility and authenticity to the journalist and by association, to his or her news organization. As Paul Frosh (2006) notes, presence "putatively unites, in the same communicative interaction, the two faces of witnessing (Peters, 2001): direct experience of an event and discourse about the event to others who were not there." Journalists' 
seeing with their own eyes and their personal experiences at the scene authorize the narrative they communicate to distant audiences.

Eyewitnessing is an idea on which journalism's collective self-image is built and by which journalists render their work meaningful for themselves (Allan, 2013, p. 58; Hanitzsch, 2007, p. 369; Zelizer, 2007). As Zelizer (2007, p. 408) notes, eyewitnessing is a cultural practice for underscoring and maintaining journalism's authority of making truth claims. Eyewitnessing offers a unique position to make claims about reality: The journalists' presence serves as an assurance of the authenticity and the significance of the event. In a similar way as suffering serves as a guarantee of the authenticity of the witness (Peters, 2001, p. 713), the exposure to the risk and potential bodily harm involved in reporting from dangerous zones helps establish the journalist's authority and virtue (Allan \& Zelizer, 2004; Creech, 2017; Peters, 2001).

In professional journalism, witnessing is most commonly understood and performed in the sense of eyewitnessing, which is in agreement with the professional discourse on objectivity. As Tait (2011, p. 1232) argues, the traditional concept of eyewitnessing casts the journalist as a detached observer who narrates events, as they actually occur, to the news audience. In contrast to bearing witness, eyewitnessing, thus, is not tied to a moral obligation and affective engagement but can be understood in terms of facts, accuracy and truth-telling (Carlson, 2009; Mortensen, 2015; Zelizer, 2004). These two understandings of witnessing are firmly separated in BBC News correspondent Kate Adie's recollections of reporting from a war zone. For Adie, rather than advocating for particular forms of action, witnessing is "the only way you can stand by your words afterwards, the only guarantee that you can give your listeners, or viewers, or readers. You saw it, you heard it, you are telling the truth as far as you know" (Adie, 1998, p. 47, as cited in Allan \& Zelizer, 2004, p. 5).

Journalistic eyewitnessing has the juridical connotation of seeing with one's own eyes, whereas bearing witness has the religious (or political or ethical) connotation of testifying to 
experiences of suffering and survival that cannot be seen or reduced to historical facts (Oliver, 2004; Peters, 2001). However, even if eyewitnessing and bearing witness have different meanings, they are not mutually exclusive but could be seen as representing different dimensions of witnessing. This is in line with Chouliaraki's (2013, p. 140) observation that journalistic witnessing requires objective and reflexive dimensions: Journalists are expected to witness events as proof of the facts on suffering and as an emotive testimony to the "unspeakable" horror of suffering. Eyewitnessing can also be understood as a precondition for moral engagement. As Cottle (2013) notes, a journalist's presence at the event can lead to a deeper understanding and felt commitment to communicate to others the plight of those whose suffering has been personally observed. Journalists involved in war or disaster reporting need to constantly negotiate this paradox between the traditional normative constructions of journalism and the committed narration that underwrites the idea of witnessing (Pantti, Wahl-Jorgensen \& Cottle, 2012, pp. 103-109).

War correspondents and photojournalists are traditionally the most esteemed among their peers because they handle "real journalism"- eyewitness-based reporting from the field in an era when journalists are increasingly tied to their desks. However, as extensive literature shows, war and conflict reporting is characterized by a number of moral-emotional challenges and tensions. When faced with atrocities and suffering, observing objectively and impartially becomes difficult. In Stephen Jukes' (2017) words, covering traumatic news stories is a struggle between "on the one hand a virtually hard-wired notion of what it is to be a professional journalist and, on the other hand, a visceral, empathic often instinctive affective dimension of practice." The key questions are how to deal with subjective emotional experiences and what stance to take toward making moral appeals (Ashuri \& Pinchevski, 2009).

One strand of journalism literature addresses journalists' witnessing of conflict as a potentially traumatizing endeavor (e.g., Feinstein et al., 2002; Jukes, 2017; Rentschler, 2009). Journalists' exposure to trauma has increasingly received attention as therapeutic perspectives have 
gained a foothold in different domains of public life. The literature emphasizes the personal emotional difficulties involved in being exposed to the violent events the journalists are covering and receiving traumatic accounts of those events. Rentschler (2009, pp. 158-159) observes the discursive change from defining witnessing in terms of detached eyewitnesses to describing journalists as traumatized witnesses, thus recoding journalists' labor in terms of its emotional cost. This discursive move underlines journalists' affective involvement in the reported events and issues, implicitly challenging "the illusion of detached and heroic models of reporting on the front lines" (p. 160).

Literature regarding journalists and trauma has focused on the personal emotional cost of witnessing violent and tragic events. There has been less research on the potential impact of covering such events on journalists' editorial decisions. Stephen Jukes (2017) argues that the position of detachment is not only about maintaining the normative values of journalism but functions also to shield the journalist from the horrors he or she may witness while covering conflicts and disasters. However, Jukes shows that as an affective practice detachment is fragile: When it breaks down, journalists either become more emotionally engaged in the story and approach eyewitnesses with increased empathy, or alternatively, journalists feel repelled by what they are witnessing.

\section{Audiences as witnesses}

In the foundational work Seeing Things: Television in the Age of Uncertainty (2000), John Ellis opened up the discussion of how media technologies are transforming the scope and nature of witnessing. Ellis conceptualized television audiences as a collective engaged in the domestic act of witnessing. This "media witnessing” entails moral responsibility because of the audiences' increased awareness of atrocities around the world. Audiences, however, are powerless spectators 
who feel complicit with the cruelties they witness. Televised events that are inescapably incomplete incite "curiosity, revulsion and the usually frustrated or passing desire for action" (p. 80). Ellis's theory of media witnessing contributed to the understanding of who is a witness by releasing it from the notion of a traumatized firsthand witness speaking on behalf of the collective (Mortensen, 2015).

The performance of media in the positioning of media audiences as witnesses to depicted events, that is, rendering atrocities and suffering as occurrences that audiences should care and do something about, has been a topic of more recent scholarship in the field of media and morality (e.g., Chouliaraki, 2006; Kyriakidou, 2015; Ong, 2014; Rentschler, 2004; Silverstone, 2006). Whereas Ellis's notion of media witnessing ultimately refers to passive "seeing" or spectatorship or voyeurism, these studies are based on the idea that global media allow new emotional connections and may invoke an active moral response by providing images of injustices and suffering (e.g., Boltanski, 1999; Chouliaraki, 2006; Silverstone, 2004). These studies establish a crucial link between the media narrative and the audience's emotional engagement or action and between the narrative and indifference or inaction.

One strand of literature has examined the relationship between media representations and the development of a cosmopolitan sensibility, referring to the capacity to imagine and empathize with the suffering of distant others (e.g. Chouliaraki, 2006; Silverstone, 2003). Media scholars have asked what kind of media representations could lead to cosmopolitan sensibilities and new emotional bonds with distant others. Chouliaraki $(2006,2013)$ understands news texts, with their choices of images, words and framings, as moral proposals for audiences to feel and act toward instances of suffering. Some types of news, she argues, block empathy for the suffering of people who are different from "us," while some cultivate cosmopolitan solidarity by addressing their audiences as a community of common humanity and inviting them to act upon the plight of nonWestern others. Roger Silverstone $(2003,2007)$ introduced the notion of the "proper distance" as a 
tool for evaluating the morality of the mediation of suffering. The idea of the proper distance includes that media texts create a sense of emotional closeness between audiences and distant sufferers. However, Silverstone insisted that audiences need to maintain enough critical distance to recognize the agency and difference of those represented (2006, pp. 80-105).

The majority of witnessing research has examined the success of media texts - in particular, television and printed news - to constitute moral audiences, rather than the actual moral responses of audiences to the events the audiences encounter through various forms of mediation. Studies on media witnessing typically ask whether news reports or other witnessing texts successfully bear witness to traumatic events (Frosh, 2006; Frosh \& Pinchevski, 2009). Successful journalistic reports can be assessed in how they use different textual and technological strategies to attribute authenticity and trust to representations of brutality, and how the reports succeed in creating a sense of presence ("being there") and consequently, an affective response from audiences.

Recent research has investigated how audiences in different contexts and socio-historical conditions respond to mediated witnessing (Kyriakidou, 2015; Ong, 2015; Scott, 2014). Jonathan Ong (2014, p. 189) argues that literature on media witnessing assumes that the witness is a middleclass Westerner who is geographically, socially and culturally distant from the experience of suffering. Ong underlines that the literature of witnessing has not paid attention to how differences in the class, gender, age and ethnicity of audiences play out in different audiences' responses to the representations. He shows in his study of Filipino audiences' everyday encounters with media representations of suffering that audiences' emotional responses and moral judgments are strongly shaped by their class position: While middle-income Filipinos' lay moralities are premised on social denial of suffering and thus, blocking moral responsibility, low-income Filipinos establish an intense emotional connection to other people's stories of suffering. 


\section{Citizen witnessing}

The witnessing by journalists and audiences is centrally connected to the availability of and developments in media technologies. In recent years, research on how media witnessing and the journalist's professional role as an eyewitness have changed, due to new digital recording technologies, has flourished. The proliferation of mobile devices and social networking sites has turned everyone into a potential witness and testimony producer (Frosh \& Pinchevski, 2014, p. 608). Whereas traditionally, witnesses appearing in news reports were carefully selected by journalists to represent a collective experience and to fit the conventions of news narratives, in the present-day media landscape, individuals and organizations outside the institutionalized media have increasingly assumed the role of witnesses (Frosh \& Pinchevski, 2009). Today's eyewitnesses are themselves capable of creating and distributing media content, without mediators functioning as gatekeepers that determine who qualifies as a witness and counterbalance the eyewitness's subjective position with their truth-telling rituals and ethical rules (Allan, 2013; Ashuri \& Pinchevski, 2009, p. 139; Mortensen, 2015; Thomas, 2009, p. 101; Zelizer, 2007, p. 421).

Keeping the focus on professional journalism, it is important to ask how witness accounts that thrive on social media platforms have transformed journalists' own practice of witnessing. Zelizer (2007, p. 422) argues that the news media have subcontracted the role of the eyewitness to private citizens with abundant capacities to use various kinds of digital tools. There seems to be agreement that delegating the role of the eyewitness to citizens has reduced journalism's centrality as an eyewitness to major events (e.g., Allan, 2013; Chouliaraki, 2010; Zelizer, 2007). However, other reasons contribute to the breakup of journalism's eyewitnessing monopoly. Not only activist groups and citizens in disaster and conflict-stricken zones but also various nongovernment organizations have taken on the roles of testimony producers and "strategic witnesses" to human suffering (Ristovska, 2016). Another factor that undoubtedly contributes to the "crisis" of witnessing in professional journalism is that for the young generations who have grown up with 
social media, traditional media organizations do not necessarily appear as the center of society—the point of access to the center of real meaning and authoritative knowledge (cf. Couldry, 2003).

It has been stated that the potential of so-called citizen witnessing lies in the insertion of ordinary, marginalized voices in Western journalism. From this democratizing perspective, professional journalists have embraced citizen eyewitness accounts as significant contributions to the visibility of disasters and political conflicts that otherwise might pass unreported and unnoticed by the world, especially when the events are sudden or journalists' access is restricted (AndénPapadopoulos \& Pantti, 2013). As scholars have noted, because of the felt effect of immediacy and “thereness" (Ellis, 2009), audience eyewitness photographs and videos, in particular, have become important for marking an on-site presence. They strengthen journalism's authority by providing a sense of being there ("even when that presence has been questionable") for news organizations (Zelizer, 2007, p. 412). At the same time, the often unidentified and unverifiable images unavoidably call into question journalistic authority and the truthfulness of the narratives.

The question of authenticity has been a recurring theme in the discussion on citizen eyewitnessing, not unlike in journalistic witnessing. Witnessing can be theorized as a competition for authenticity and for earning the trust of the addressed audiences (Ashuri \& Pinchevski, 2009, p. 137). Where does the authority of citizen witnessing come from? Citizen images' rhetoric of authenticity arises, first, from the fact that the content is generated by individuals involved in the events rather than by journalists as allegedly detached observers. Second, professional journalists believe that the raw aesthetics of citizen photo-reportage lend intimacy and an aura of reality to journalistic storytelling (Williams, Wardle \& Wahl-Jorgensen, 2011). Ontological and textual aspects raise concerns. On one hand, citizen eyewitnesses can be parties in a particular conflict and may attempt to promote their narratives of events through mainstream-media publicity (AndénPapadopoulos \& Pantti, 2013). Thus, citizen footage raises concerns about the identities and the moral status of the witnesses to suffering. On the other hand, the arrival of digital technologies has 
challenged the status of photos as evidence because altering or manipulating images has been made easy (e.g., Ellis, 2012, p. 184).

Citizen images are considered particularly effective in appealing to viewers' emotions (Reading, 2009). Chouliaraki (2010) argues that it is no longer only the verification of facts and sources that makes news trustworthy but also the authority of genuine emotion and first-person experience. In this sense, remediating eyewitness video footage and photographs by actors on the scene can be interpreted as a disruption of the professional discourses on objectivity. Citizen reportage of significant news events is appealing to news organizations and audiences because it provides unedited emotional accounts that evoke a sense of proximity to the events covered.

However, the potential of amateur images to elicit moral responses to the suffering and create new witnesses, based solely on the sense of authenticity and proximity that the images offer, has been questioned (Ashuri \& Pinchevski, 2009, p. 140). Journalists themselves share the idea that although citizen images have an inherent emotional proximity, they also contain a moral risk of the loss of perspective. Journalists believe that only professionally crafted narratives create emotional identification and maintain a "proper distance" to witnessed events (Andén-Papadopoulos \& Pantti, 2013; Ashuri \& Pinchevski, 2009, p. 140). Journalists' discourse on proximity resonates with Silverstone's (2004, p. 444) notion that to enable moral responsibility, media reporting of suffering "needs to be close but not too close, distant, but not too distant."

Clearly, the ubiquity of mobile devices and social media has emerged as an important tool for various groups and individuals to gain visibility and bear witness to human rights abuses. Rae, Holman and Nehery (2018) examine the "self-represented witnessing" of detained asylum seekers in Australia who use social media to bear witness to their own suffering and address an online audience directly because they have no access to journalists. However, only when their witness accounts are remediated by mainstream media are the detainees able to reach a wider audience. The study of the detainees' attempts to get their voices heard through personal testimonies illustrates the 
new research on witnessing that highlights the intersecting cultural, social, technological and racial forces that inspire marginalized people to independently bear witness to human rights violations. Studying the outpouring of "black witnessing" following recent instances of police brutality in the United States, Richardson (2017) argues that black witnesses - firsthand witnesses who film police violence and secondhand witnesses who take action after seeing such witness videos - help create a long narrative of human rights violations. Using black Twitter as a news wire and addressing diverse black audiences, mobile black witnessing advocates for African American civil rights and commemorates the long history of atrocities.

\section{Conclusion and directions for further research}

Journalism witnessing can denounce violence and bring the plight of others home to the point of mobilizing public opinion and action. It would be a mistake to undermine the role of journalism witnessing in this world characterized by mass suffering, disasters and atrocities. However, journalism's potential to cultivate empathy and a moral response to others' suffering is continuously called into question. In this chapter, I discussed how witnessing has been conceptualized in journalism and media scholarship, and how technological developments have shaped these conceptualizations. In recent years, the literature has focused on the relationship between citizen reportage and professional journalism, but evolving media technologies have generated new questions. Currently, the capacity of virtual reality (VR), which affords an imaginative first-person experience of another time and place, to produce "immersive witnessing" in journalistic and humanitarian contexts has received scholarly attention (Frosh, 2016; Nash, 2017). In the context of digital media, the production of the experience of presence remains essential to theorizing the exact nature of witnessing. What implications do new forms of presence, either in the media or through the media, have for our moral response to others' suffering? Future research should pay attention to the moral affordances of different digital platforms and interfaces. 
Technological change has ushered in new journalistic forms that allow for more subjective and emotional forms of narrative (Wahl-Jorgensen, 2013). Twitter is an example of a media form that encourages subjective voices and personal expression to generate emotional engagement. Research has shown that there is an expectation of more personal reporting on Twitter that allows for more subjectivity and expression of emotion than are typically acceptable in news reporting. However, such journalistic forms have long existed. In a 2011 study, Tait found that a columnist at the New York Times was allowed to exceed the normative journalistic position of impartiality and "to induce in them [his readers] an approximation of his own embodied experiences" (p. 1228). Tait makes a distinction between eyewitnessing and bearing witness: The former is based on the paradigm of detachment that precludes the reporter's own voice and the other's voice, the latter on personal affectedness and explicit moral stance. She rightly argues that the journalistic practice of taking responsibility requires acknowledging the affectivity and subjectivity of bearing witness. However, as Oliver (2004, p. 85) states, "we need both poles of witnessing," one of which is eyewitnessing, the producer of historical facts, and the other subjective testimony, with its moral vision, emotional force - and potential inaccuracies.

More attention should be paid to the analysis of the relationship between these two positions in journalism and their scholarly study. Are these two approaches, based on different ontological outlooks, contradictory? In the contexts of large-scale disasters and conflicts, the boundaries between objective and subjective storytelling are very likely to break or leak, even within one story. However, there is surprisingly little recent research (since the previous classical studies on investigative reporting and civic journalism) on what journalists' taking moral responsibility means in specific contexts, journalistic genres and news platforms, and how journalists in practice negotiate the two seemingly competing approaches when reporting on specific traumatic events (Cottle, 2013; Wahl-Jorgensen, 2013). 
As the now thriving research on citizen witnessing has shown, digital platforms enable new forms of witnessing that are no longer tied to professional journalism's symbolic power (Mortensen, 2015; Richardson, 2017). The rhetoric of citizen or amateur witnessing may conceal the parallel development of the professionalization of bearing witness in the global media environment. Professionalization highlights the process through which witness testimonies of violence are turned into comprehensible and meaningful packages and targeted at the desired institutional audiences, including media outlets and humanitarian organizations. Such "strategic witnessing" (Ristovska, 2016), then, continues to be dependent on the cultural authority that professional journalism still enjoys. The amateurization and strategic targeting of witnessing texts signal a new era of witnessing, one that is characterized by suspicious reading and occupied with “false witnessing” (Smith \& Watson, 2012).

Existing research has emphasized that the perceived authenticity of witnesses' accounts is crucial in generating empathy and resisting acts of denial. Acts of witnessing always involve an audience that requires evidence of the truth of testimony (Peters, 2001). As we have seen, the literature points to the physical presence and personal experience in granting authenticity to witnesses and their testimonies. However, although anonymous social media footage, especially that coming from closed countries such as Syria, may provide critical visual evidence, the footage has also raised the importance of verification. The era of the "false witness" is summed up in Wardle's (2014, p. 29) comment: “Any journalist or humanitarian professional has to start off by assuming a piece of UGC [user-generated content] is false." In current discussions about the fabrication and verification of digital texts that purport to bear witness, the focus has been on specific cases or texts, and little attention has been given in journalism studies to this hostile culture of suspicion and how it shapes or constricts journalists' practices of witnessing. Testimonial narratives have become indispensable to a wide variety of political projects in the contemporary media environment (Ashuri \& Pinchevski, 2009, p. 133; Givoni, 2014). However, Internet forums 
and social media have provided new contexts not only for representing human rights violations and suffering but also for suspicious and hateful readings of witnessing texts. How news reporting contributes to or resists this culture of suspicion is an essential area of research because news coverage continues to be crucial to giving a voice to suffering. 


\section{References}

Allan, S., \& Zelizer, B. (2004). Rules of engagement. In S. Allan \& B. Zelizer (Eds.), Reporting war: Journalism in wartime (pp. 3-21). London: Routledge.

Allan, S. (2013). Citizen witnessing: Revisioning journalism in times of crisis. Cambridge: Polity Press.

Ananny, M. (2015). Creating proper distance through networked infrastructure: Examining Google Glass for evidence of moral, journalistic witnessing. In M. Carlson \& S.C. Lewis (Eds.), Boundaries of journalism: Professionalism, practices, participation (pp. 83-99). New York, NY: Routledge.

Andén-Papadopoulos, K., \& Pantti, M (2013). Re-imagining crisis reporting: Professional ideology of journalists and citizen eyewitness images. Journalism, 14(7), 960-977. doi:10.1177/1464884913479055

Ashuri, T., \& Pinchevski, A. (2009). Witnessing as a field. In P. Frosh \& A. Pinchevski (Eds.), Media witnessing: Testimony in the age of mass communication (pp. 133-157). London: Palgrave.

Boltanski, L. (1999). Distant suffering. Morality, media and politics. Cambridge: Cambridge University Press.

Bradford, V. (2014). Witnessing time: rhetorical form, public culture, and popular historical education. Rhetoric Society Quarterly, 44(3), 204-219. doi:10.1080/02773945.2014.911558

Butler, J. (2004). Precarious life: The powers of mourning and violence. London: Verso.

Butler, J. (2009). Frames of war: When is life grievable? London: Verso. 
Carlson, M. (2009). The reality of a fake image: News norms, photojournalistic craft, and Brian Walski's fabricated photo. Journalism Practice, 3(2), 125-139. doi: $10.1080 / 17512780802681140$

Chouliaraki, L. (2006). The spectatorship of suffering. London: SAGE.

Chouliaraki, L. (2009). Witnessing war: Economies of regulation in reporting war and conflict. The Communication Review, 12, 215-226.

Chouliaraki, L. (2010). Ordinary witnessing in post-television news: Towards a new moral imagination. Critical Discourse Studies, 7(4), 305-319.

Chouliaraki, L. (2013) Re-mediation, inter-mediation, transmediation. Journalism Studies, 14(2), 267283.

Cottle, S. (2013). Journalists witnessing disaster: from the calculus of death to the injunction to care. Journalism Studies, 14(2), 232-248.

Cottle, D. (2014). Rethinking media and disasters in a global age: What's changed and why it matters. Media, War \& Conflict, 7(1), 3-22. doi:10.1177/1750635213513229

Couldry, N. (2003). Media rituals: A critical approach. London: Routledge.

Creech, B. (2017). Bearing the cost to witness: the political economy of risk in contemporary conflict and war reporting Media, Culture \& Society, 40(4), 567-583. doi:10.1177/0163443717715078

Ellis, J. (2000). Seeing things: Television in the age of uncertainty. London: I.B. Tauris.

Ellis, J. (2009). Mundane witness. In P. Frosh \& A. Pinchevski (Eds.), Media witnessing: Testimony in the age of mass communication (pp. 73-88). Basingstoke: Palgrave Macmillan. 
Ellis, J. (2012). The digitally enhanced audience: New attitudes to factual footage. In J. Gripsrud (Ed.), Relocating television: Television in the digital context (pp. 183-192). London: Routledge.

Felman, S., \& Laub, D. (1992). Testimony: Crises of witnessing in literature, psychoanalysis, and history. New York, NY: Routledge.

Frosh, P. (2006). Telling presences: Witnessing, mass media, and the imagined lives of strangers. Critical Studies in Media Communication, 23(4), 265-284. doi:10.1080/07393180600933097

Frosh, P., \& Pinchevski, A. (2009). Introduction: Why media witnessing? Why now? In P. Frosh \& A. Pinchevski (Eds.), Media witnessing: Testimony in the age of mass communication (pp. 119). Basingstoke: Palgrave Macmillan.

Frosh, P., \& Pinchevski, A. (Eds.) (2009). Media witnessing: Testimony in the age of mass communication. Basingstoke: Palgrave Macmillan.

Frosh, P. (2016). The mouse, the screen and the Holocaust witness: Interface aesthetics and moral response. New Media and Society, 20(1), 351-368. doi:10.1177/1461444816663480.

Givoni, M. (2014). The ethics of witnessing and the politics of the governed. Theory, Culture \& Society, 31(1), 123-142. doi:10.1177/0263276413488633

Jukes, S. (2017). Affective journalism - Uncovering the affective dimension of practice in the coverage of traumatic news. $\mathrm{PhD}$ Thesis, Goldsmiths University, London. Retrived from http://research.gold.ac.uk/20635/

Kitch, C. (2008). Placing journalism inside memory - and memory studies. Memory Studies, 1(3), 311-320. doi:10.1177/1750698008093796

Kurasawa, F. (2009). A message in a bottle: bearing witness as a mode of transnational practice. Theory Culture \& Society, 26(1), 92-111. doi: 10.1177/0263276408099017 
Kyriakidou, M. (2015). Media witnessing: Exploring the audience of distant suffering. Media, Culture \& Society, 37(2), 215-231. doi: 10.1177/0163443714557981

Mortensen, M. (2015). Journalism and eyewitness images: Digital media, participation, and conflict. New York, NY: Routledge.

Nash, K. (2017). Virtual reality witness: Exploring the ethics of mediated presence. Studies in Documentary Film. doi:10.1080/17503280.2017.1340796

Oliver, K. (2004). Witnessing and testimony. Parallax, 10(1), 78-87. doi:10.1080/1353464032000171118

Ong, J. (2014). "Witnessing” or "mediating” distant suffering? Ethical questions across moments of text, production and reception. Television and New Media, 15(3), 179-196. doi:10.1177/1527476412454687

Ong, J. (2015). Witnessing distant and proximal suffering within a zone of danger: Lay moralities of media audiences in the Philippines. International Communication Gazette, 77(7), 607-621. doi:10.1177/1748048515601555

Pantti, M., \& Wahl-Jorgensen, K. (2011). "Not an act of god": Anger and citizenship in press coverage of British man-made disasters. Media, Culture \& Society, 33(1), 105-122. doi:10.1177/0163443710385503

Pantti, M., Wahl-Jorgensen, K., \& Cottle, S. (2012). Disasters and the media. London: Peter Lang.

Pantti, M. (2017). The personalisation of conflict reporting: visual coverage of the Ukraine crisis on Twitter. Digital Journalism. doi:10.1080/21670811.2017.1399807

Plaisance, P. (2002). The journalist as moral witness. Michael Ignatieff's pluralistic philosophy for a global media culture. Journalism, 3(2), 205-222. doi:10.1177/146488490200300201 
Peters, J.D. (2001). Witnessing. Media, Culture \& Society, 23(6), 707-723.

doi:10.1177/016344301023006002

Rae, M., Holman, R., \& Nethery, A. (2018). Self-represented witnessing: the use of social media by asylum seekers in Australia's offshore immigration detention centres. Media, Culture \& Society, 40(4), 479-495. doi:10.1177/0163443717746229

Reading, A. (2009). Mobile witnessing: Ethics and the camera phone in the "war on terror". Globalizations, 6(1), 61-76. doi:10.1080/14747730802692435

Rentschler, C. (2004). Witnessing: US citizenship and the vicarious experience of suffering. Media, Culture \& Society, 26(2), 296-304. doi:10.1177/0163443704041180

Rentschler, C. (2009). From danger to trauma: Affective labor and the journalistic discourse of witnessing. In P. Frosh \& A. Pinchevski (Eds.), Media witnessing: Testimony in the age of mass communication (pp. 158-181). Basingstoke: Palgrave Macmillan.

Richardson, A.V. (2017). Bearing witness while black. Digital Journalism, 5(6), 673-698. doi:10.1080/21670811.2016.1193818

Ristovska, S. (2016). Strategic witnessing in an age of video activism. Media, Culture \& Society, 38(7), 1034-1047. doi:10.1177/0163443716635866

Sambrook, R. (2010). Are foreign correspondents redundant? The changing face of international news. Oxford: Reuters Institute for the Study of Journalism. Retrived from https://reutersinstitute.politics.ox.ac.uk/sites/default/files/201712/Are\%20Foreign $\% 20$ Correspondents\%20Redundant $\% 20$ The $\% 20$ changing $\% 20$ face $\% 20$ of \%20international\%20news.pdf 
Silverstone, R. (2003). Proper Distance: Towards an Ethics for Cyberspace. In G. Liestol, A. Morrison \& T. Rasmussen (Eds.), Digital media revisited: Theoretical and conceptual innovations in digital domains (pp. 469-490). Cambridge, MA: MIT Press.

Silverstone, R. (2004). Regulation, media literacy and media civics. Media, Culture \& Society, 26(3), 440-449. doi:10.1177/0163443704042557

Silverstone, R. (2006). Media and morality: On the rise of the Mediapolis. Cambridge: Polity Press.

Smith, S., \& Watson, J. (2012). Witness or false witness: Metrics of authenticity, collective Iformations, and the ethic of verification in first-person testimony. Biography - An Interdisciplinary Quarterly, 35(4), 590-626.

Tait, S. (2011). Bearing witness, journalism, and moral responsibility. Media, Culture \& Society, 33(8), 1220-1235. doi:10.1177/0163443711422460

Thomas, G. (2009). Witness as a cultural form of communication. In P. Frosh \& A. Pinchevski (Eds.), Media witnessing. Testimony in the age of mass communication (pp. 89-111). Basingstoke: Palgrave Macmillan.

Wahl-Jorgensen, K. (2013). The strategic ritual of emotionality: A case study of Pulitzer prizewinning articles. Journalism, 14(1), 129-145. doi:10.1177/1464884912448918

Wang, B. Lee, F., \& Wang, H. (2013). Technological practices, news production processes and journalistic witnessing. Journalism Studies, 14(4), 491-506. doi:10.1080/1461670X.2012.739315

Wardle, C. (2014). Verifying user-generated content. In C. C. Silverman (Ed.), Verification handbook: A definitive guide to verifying digital content for emergency coverage (pp. 24-33). Maastricht: European Journalism Centre. Retrived from http://verificationhandbook.com/downloads/verification.handbook.pdf. 
Wiesslitz, C., \& Ashuri, T. (2011) "Moral journalists": The emergence of new intermediaries of news in an age of digital media. Journalism, 12(8), 1035-1051. doi: $10.1177 / 1464884910388236$

Wieviorka, A. (1998). The era of the witness. Ithaca, N.Y.: Cornell University Press.

Wieviorka, A. (2006). The witness in history. Poetics Today, 27(2), 385-397. doi:10.1215/03335372-2005-009

Williams, A., Wardle, C. \& Wahl-Jorgensen, K. (2011). "More real and less packaged": Audience discourses on amateur news content and their effects on journalism practice. In K. AndenPapadopoulos \& M. Pantti (Eds.), Amateur images and global news (pp. 195-209). Bristol: Intellect Books.

Zelizer, B. (1998). Remembering to forget: Holocaust memory through the camera's eye. Chicago: University of Chicago Press.

Zelizer, B., \& Allan, S. (2002) Introduction: When trauma shapes the news. In B. Zelizer \& S. Allan (Eds.), Journalism after September 11 (pp. 1-24). London: Routledge.

Zelizer, B. (2002). Finding aids to the past: bearing personal witness to traumatic public events. Media, Culture \& Society, 24(5), 697-714. doi:10.1177/016344370202400509

Zelizer, B. (2004). When facts, truth, and reality are god-terms: On journalism's uneasy place in cultural studies. Communication and Critical/Cultural Studies, 1(1), 100-119. doi:10.1080/1479142042000180953

Zelizer, B. (2007). On "having been there": "Eyewitnessing" as a journalistic key word. Critical Studies in Media Communication, 24(5), 408-428. doi:10.1080/07393180701694614 
Zion, D., Briskman, L., \& Loff, B. (2012). Psychiatric ethics and a politics of compassion: The case of detained asylum seekers in Australia. Bioethical Inquiry, 9(1), 67-75.

doi:10.1177/016344370202400509 